\title{
Capacitação estratégica com readequação orçamentária para melhoria do serviço público em uma instituição federal de ensino superior
}

Ana Cristina de Albuquerque Lima Rodrigues

Professora do Departamento de Administração do Colégio Pedro II - RJ e atuante na Administração Pública Federal. Mestre em Administração pela UFRRJ

anacalr@gmail.com

https://orcid.org/0000-0002-8382-400X

Elines Tatianes Pereira dos Santos Petine

Coordenadora de desenvolvimento de pessoal na UFRRJ. Mestre em Administração pela UFRRJ

senilestar@hotmail.com

Fabio Gonçalves Rodrigues

Analista financeiro, pesquisador e professor de Administração Financeira e Orçamentária Master Business Administration em Finanças pela UNESA-RJ

fabiogr.32@gmail.com

https://orcid.org/0000-0002-3072-9551

\section{Editor Científico: José Edson Lara}

Organização Comitê Científico

Double Blind Review pelo SEER/OJS

Recebido em 05.10.2019

Aprovado em 05.12.2019

Este trabalho foi licenciado com uma Licença Creative Commons - Atribuição - Não Comercial 3.0 Brasil 


\title{
Resumo
}

Apresentamos os elementos principais deste relato (objetivo, metodologia, originalidade, principais resultados, contribuições teóricas e sociais, e palavras-chaves):

1) Título do trabalho: Capacitação estratégica com readequação orçamentária para melhoria do serviço público em uma instituição federal de ensino superior.

2) Objetivo do estudo: apresentar como se deu a primeira intervenção para capacitação estratégica de servidores aliada ao controle de gastos, em uma Universidade Federal.

3) Metodologia: foram realizados mapeamento e ajuste de processos do setor responsável pela capacitação de servidores; identificação do gap de capacitação na visão estratégica da alta gestão, no Plano de Desenvolvimento Institucional, na visão do setor de desenvolvimento de pessoas, e nas demandas dos servidores e suas chefias. Por último, foi realizado estudo para readequação orçamentária.

4) Originalidade/Relevância: na intervenção relatada se dá ao (a) evidenciar que o aperfeiçoamento funcional de servidores possui relação direta com a melhoria do serviço público, sem, contudo, negligenciar o compromisso com gastos e alinhamento das diretrizes estratégicas institucionais; (b) antever o Decreto 9.991/2019, apesar da capacitação de pessoal público federal ser regida à época, pelo Decreto 5.707/2007.

5) Principais resultados: melhoria na utilização dos recursos públicos; valorização funcional; e formação de multiplicadores.

6) Contribuições teóricas/metodológicas: respectivamente, o aprofundamento do estudo em orçamento público pelos profissionais de gestão de pessoas e a capacitação estratégica aliada à reorganização orçamentária.

7) Contribuições sociais / para a gestão: unir capacitação e responsabilidade com os gastos, e seu retorno em melhores serviços para a população.

Palavras-chave: Capacitação estratégica; Orçamento público federal.

\section{Strategic training with budget adjustment to improve public service in a federal higher}

\section{education institution}

\begin{abstract}
We present the main elements of this report (objective, methodology, originality, main results, theoretical and social contributions, and keywords):

1) Title of the paper: Strategic training with budget adjustment to improve public service in a federal higher education institution.

2) Objective of the study: to present how the first intervention towards the strategic training of public servants was combined with the control and effective use of expenses in a Federal University.

3) Methodology: processes were mapped and adjusted in the sector responsible for the training of servers; Identification of the capacity gap in the strategic view of top management, the Institutional Development Plan, the view of the people development sector, and the demands of employees and their managers. Finally, a study was conducted for budget readjustment.

4) Originality / Relevance: in the reported intervention, it is shown that the functional improvement of servers is directly related to the improvement of public service, without, however, neglecting the commitment to spending and alignment of institutional strategic
\end{abstract}


guidelines; (b) envisage Decree 9.991 / 2019, although the training of federal public personnel was governed at the time by Decree 5.707 / 2007.

5) Main results: improved use of public resources; functional appreciation; and formation of multipliers.

6) Theoretical / methodological contributions: respectively, the deepening of the study in the public budget by the people management professionals and the strategic training combined with the budget reorganization.

7) Social / management contributions: combine training and accountability with spending, and their return on better service to the population.

Keywords: Strategic capacity building; Federal public budget.

\section{Capacitación estratégica con ajuste presupuestario para mejorar el servicio público en}

\section{una institución federal de educación superior}

\section{Resúmen}

Presentamos los elementos principales de este informe (objetivo, metodología, originalidad, resultados principales, contribuciones teóricas y sociales y palabras clave):

1) Título del trabajo: Capacitación estratégica con ajuste presupuestario para mejorar el servicio público en una institución federal de educación superior.

2) Objetivo del estudio: presentar cómo se realizó la primera intervención para la capacitación estratégica de los empleados combinada con el control de costos en una Universidad Federal.

3) Metodología: se mapearon y ajustaron procesos en el sector responsable de la capacitación de servidores; Identificación de la brecha de capacidad en la visión estratégica de la alta dirección, el Plan de Desarrollo Institucional, la visión del sector de desarrollo de personas y las demandas de los empleados y sus gerentes. Finalmente, se realizó un estudio para el reajuste presupuestario.

4) Originalidad / Relevancia: en la intervención informada, se muestra que la mejora funcional de los servidores está directamente relacionada con la mejora del servicio público, sin descuidar, sin embargo, el compromiso con el gasto y la alineación de las directrices estratégicas institucionales; (b) prevea el Decreto 9.991 / 2019, aunque la capacitación del personal público federal se regía en ese momento por el Decreto 5.707 / 2007.

5) Resultados principales: uso mejorado de los recursos públicos; apreciación funcional; y formación de multiplicadores.

6) Contribuciones teóricas / metodológicas: respectivamente, la profundización del estudio en el presupuesto público por parte de los profesionales de gestión de personas y la capacitación estratégica combinada con la reorganización del presupuesto.

7) Contribuciones sociales / de gestión: combinan la capacitación y la rendición de cuentas con el gasto y su retorno a un mejor servicio a la población.

Palabras claves: Capacitación estratégica; Presupuesto publico federal. 


\section{Introdução}

A capacitação dos servidores técnicos administrativos de uma Universidade Federal se torna estratégica em um contexto de profundas mudanças estruturais e políticas, em um contexto de contenção de gastos públicos, em um contexto de alta rotatividade e envelhecimento do corpo funcional.

Diante do cenário apresentado, a coordenação de desenvolvimento de pessoal da Universidade foi legitimada por seus gestores a propor uma capacitação alinhada com os objetivos organizacionais e comprometida com o controle e utilização efetiva dos gastos públicos.

O Decreto 5.707 já instituía, desde 2007, a Política Nacional de Desenvolvimento de Pessoal, a ser implementada pelos órgãos e entidades da administração pública federal direta, autárquica e fundacional, alinhando melhoria da eficiência, eficácia e qualidade dos serviços públicos prestados ao cidadão ao desenvolvimento permanente do servidor público com racionalização e efetividade dos gastos com capacitação.

Assim, a equipe de trabalho necessitou diagnosticar a situação, propor ações de capacitação e nova proposta orçamentária, de forma que os gastos se tornassem eficientes e eficazes, retornando em melhorias no serviço público ofertado. O problema norteador foi: como aprimorar o aproveitamento do orçamento para a capacitação, capacitando estrategicamente?

Diante disto, o relato apresenta, além da introdução, uma seção contendo o contexto da capacitação e seu orçamento na Universidade antes da intervenção; uma terceira seção com literatura selecionada para entendimento do problema; a quarta seção com a metodologia do diagnóstico da situação e a proposta de intervenção; a quinta seção com os resultados apresentados 18 meses após a intervenção, e analisados com base na literatura apresentada; e finalmente, a sexta seção contendo considerações finais e propostas de continuidade da pesquisa.

\section{Contexto da capacitação e seu orçamento na universidade antes da intervenção}

Antes da intervenção aqui relatada, as necessidades de capacitação eram identificadas através de pesquisas diretamente aos servidores com relação ao que gostariam de aprender, 
como assuntos de capacitação. Esta prática trazia resultados diversos como sugestões de cursos que, muitas vezes, nada tinham relação com a missão da Universidade e suas necessidades. Algumas vezes eram necessidades do servidor que poderiam ou não ser aproveitadas em serviço.

E do ponto de vista orçamentário, as capacitações não eram previamente mensuradas para proposta, cabendo à Coordenação um valor fixo do orçamento não reajustado há muitos anos. Valor que, além de congelado, era aproveitado por um grupo seleto de servidores que se interessava em realizar seu serviço de forma correta e gostaria de aprender mais, mas gastavam muito para a pouca quantidade de capacitados, e os demais, que alegavam não conhecer os caminhos para solicitar recursos para capacitação, ou não se interessavam.

Este orçamento de capacitação era de $\mathrm{R} \$ 300.000,00$, divididos nas modalidades cursos externos, cursos in company e cursos internos, como mostra o Quadro 1. O gasto com inscrições em cursos externos foi estancado segundo semestre de 2017, ano de estudo desta intervenção, pois o valor gasto já havia ultrapassado o percentual orçado, e ainda, capacitando apenas $6 \%$ dos servidores técnico-administrativos, que se concentravam nas áreas de Departamento de Pessoal, Licitações e Finanças. Com relação aos cursos e eventos internos, foram realizadas 11 atividades de capacitação, todas no segundo semestre, na tentativa de se realizar atividades de capacitação com menor custo, abrangendo um maior número de pessoas.

\section{Tabela 1}

Distribuição Orçamentária para capacitação antes da intervenção realizada.

\begin{tabular}{|c|c|c|c|}
\hline Modalidades & $\begin{array}{c}\text { Fixado } \\
\text { (R\$) }\end{array}$ & Pago (R\$) & $\begin{array}{c}\text { Servidores } \\
\text { Capacitados }\end{array}$ \\
\hline Cursos externos & $120.000,00$ & $164.893,80$ & 74 \\
\hline Cursos e eventos elaborados internamente & $90.000,00$ & $55.106,20$ & 596 \\
\hline Cursos Incompany & $90.000,00$ & - & - \\
\hline TOTAL & $300.000,00$ & $220.000,00$ & 670 \\
\hline
\end{tabular}

Os valores gastos não eram controlados até seu efetivo pagamento à empresa prestadora de serviço de capacitação, gerando sobras indevidas e passíveis de recolhimento pelo governo federal, com a correta impressão de que não eram necessárias. 
É interessante ressaltar que o orçamento para a Ação 4572 não previa recursos para diárias a passagens de capacitação - que eram efetivamente gastos quando os servidores faziam os cursos externos, aumentando assim, os gastos nesta modalidade, mostrados no Quadro 1. Não havia controle orçamentário específico para isto, e tais valores se confundiam com os valores gastos em toda a Universidade.

\section{Entendimento do contexto com base na literatura}

\subsection{Orçamento público federal}

O processo de orçamento vigente no Brasil é chamado de Orçamento-programa, cujo conjunto de conceitos e disposições técnicas foi sistematizado originalmente pela Organização das Nações Unidas (ONU), extraído da experiência federal americana. Foi no final dos anos 50 e início dos 60, após intensas programações de reuniões e debates, que a ONU, através de diversos organismos internacionais incluindo a Comissão Econômica para a América Latina (CEPAL), compilou um modelo de Orçamento-programa para seus países membros (GIACOMONI, 2007).

O Orçamento-programa constitui um sistema que enfatizam as realizações do governo como cumprimento de suas funções, e os bens e serviços adquiridos por ele, como os meios ou ferramentas este cumprimento de funções (GIACOMONI, 2007).

Neste modelo de orçamento os componentes são articulados e organizados, com a programação de gastos de cada instituição, agrupados hierarquicamente pelos órgãos, até chegar nos grandes Ministérios, por exemplo. Estes gastos programados são compilados em proposta/projeto de lei orçamentária anual (PLOA) e apresentados para discussão, votação e aprovação orçamentária no Poder Legislativo. Após exame, a proposta orçamentária pode ou não ser aprovada e, da forma como for aprovada, se torna a Lei de Orçamento Anual (LOA) que especifica e descreve a dotação orçamentária de cada instituição que compõe a administração direta, indireta, autárquica, fundacional, de seguridade social e investimento das empresas em que o Poder Público detenha a maioria do capital social com direito a voto (GIACOMONI, 2007).

É interessante ressaltar que cada proposta orçamentária deve apresentar motivos para os gastos, sincronia com o Programação Plurianual (PPA), que destaca as prioridades e metas a serem executadas pelo governo federal, e com a Lei de Diretrizes Orçamentárias (LDO), que fornece orientações para a elaboração da LOA. A mensuração dos resultados propostos 
nos orçamentos anuais deve ser praticada por cada instituição e órgão gestor (GIACOMONI, 2007).

As Instituições Federais de Ensino Superior (IFES) são instituições públicas mantidas sob responsabilidade do Poder Executivo Federal, possuem autonomia de gastos atendendo às normas gerais e recursos disponíveis, e seu orçamento integra a parte fiscal da LOA, controlado através de todo este sistema orçamentário (Brasil, 1996).

$\mathrm{Na}$ IFES do contexto desta pesquisa, a coordenação, a fiscalização e a superintendência das atividades de planejamento e orçamento cabem ao Reitor, de acordo com as diretrizes do Ministério da Educação, ouvidas as Unidades Acadêmicas, Unidades Administrativas da Universidade e Diretorias dos Campi (UFRRJ, 2012), que formam a Comissão de Elaboração e Acompanhamento Orçamentário.

E desde a proposta orçamentária, os gastos públicos devem ser organizados de acordo com sua Função, Subfunção, Programa e Ação, onde as duas primeiras classificações simbolizam os níveis de agregação; cada Programa representa as soluções às demandas da sociedade mediante um conjunto articulado de projetos; e as Ações representam as atividades práticas para o alcance dos objetivos (GIACOMONI, 2007; SOF, 2017).

As despesas com capacitação de servidores públicos federais são despesas correntes ${ }^{\mathrm{i}} \mathrm{e}$ fazem parte do Programa 0791: Valorização do Servidor Público, Ação de número 4572: Capacitação de Servidores Públicos Federais em Processo de Qualificação e Requalificação. Sua base legal é o Decreto $\mathrm{n}^{\circ} 5.979 / 2006$, e tem por objetivo o financiamento de atividades voltadas ao treinamento de servidores, incluindo custeio de eventos, cursos, seminários, congressos, pagamento de passagens e diárias quando em viagem para capacitação, e outras despesas relacionadas ao assunto. O objetivo de tais atividades é promover a qualificação de pessoal para a melhoria continuada dos processos de trabalho, e crescimento profissional ${ }^{\mathrm{ii}}$.

\subsection{Bases legais da Ação 4572 - Capacitação de Servidores Públicos Federais}

Nos Estados Unidos, as principais competências definidas para os executivos públicos foram a capacidade de liderar mudanças e pessoas para resultados orientados, a capacidade de gestão financeira, a gestão de tecnologia de informação; e a capacidade de comunicação e construção de alianças. No Reino Unido, tais competências foram definidas como a capacidade de empregar experiências para melhorar resultados, pensando estrategicamente para atingir objetivos. No Canadá enfatizam-se as competências intelectuais - capacidade 
cognitiva e criatividade; as competências de gestão - trabalho em equipe, consciência organizacional - as competências sobre relações interpessoais - desenvolvimento de parcerias e comunicação - e as competências individuais - resistência ao estresse, ética, valores, personalidade, flexibilidade comportamental e autoconfiança. No Brasil, a Escola Nacional de Administração Pública (ENAP) tem grande parceria com a Escola Canadense do Serviço Público, mantendo a mesma linha de pensamento (AMARAL, 2006).

No contexto brasileiro a capacitação e o desenvolvimento de competências dos servidores públicos possuem relação direta com a melhoria dos serviços públicos, sendo a capacitação estratégica para a nação. Isto por que vivemos em um contexto de problemas sociais e econômicos, e acentuado grau de desigualdade social (AMARAL, 2006).

A autora escreveu imediatamente após a publicação do Decreto 5.707/2006, que institui a Política Nacional de Desenvolvimento de Pessoal para a Administração Pública Federal. Esta Política tem como objetivos o permanente desenvolvimento do servidor público, o gerenciamento das ações e gastos com capacitação, e a adequação das competências requeridas dos servidores aos objetivos das instituições (BRASIL, 2006).

Com tais objetivos este Decreto procurou mudar a gestão pública, inovando e aprimorando a capacidade de atender mais e melhor, agora incluindo os servidores e mobilizando seus talentos (AMARAL, 2006).

E para alinhar o desenvolvimento dos servidores com a carreira, o Decreto estabelece o incentivo à inclusão das atividades de capacitação como requisito para a promoção funcional do servidor na carreira, e instrui que os órgãos e entidades da administração pública federal deverão oferecer ações voltadas à habilitação de seus servidores para o exercício de cargos de direção e assessoramento em seus planos de capacitação, com prioridade nos programas de desenvolvimento de recursos humanos (BRASIL, 2006).

Outra base legal para a Ação 4572, no contexto desta pesquisa, está no Plano de Carreira dos Cargos Técnico-Administrativos em Educação (PCCTAE), Lei 11.091/2005, que dispõe sobre a estruturação do Plano de Carreira dos Cargos Técnico-Administrativos em Educação, no âmbito das IFES.

O PCCTAE oferece a possibilidade de três formas de aumento salarial: o incentivo à qualificação, a progressão por mérito e a progressão por capacitação, que incluem conclusão de estudo superior formal, cursos de capacitação, e avaliação de desempenho. Aproveitando este incentivo legal do Plano de Carreira, os cursos realizados e o consequente ganho 
percentual - tanto em qualificação quanto em capacitação - podem ser estrategicamente oferecidos de acordo com a necessidade institucional.

Outra base legal para a Ação 4572, é a Lei 8.666/93 que institui normas para licitações e contratos da Administração Pública. Não é prudente esquecer que as ações de capacitação devem ser vistas como modalidades de contratação. E todos os gastos do serviço público, mesmo que já previstos em orçamento, devem estar de acordo com a legislação de contratações.

\subsection{Capacitação estratégica}

Retomando o assunto do contexto brasileiro e a necessidade do desenvolvimento de pessoas direcionado a melhoria dos serviços públicos, as IFES atuam em cenário de mudanças sociais, políticas e econômicas, e necessitam de adequada gestão de pessoas e profissionalismo na gestão pública. E o aumento da complexidade do trabalho e da necessidade de efetividade fomentou o debate sobre gerência pública (PEREIRA; SILVA, 2011).

No modelo de Administração Pública Gerencial, que ganhou força a partir dos anos 90 com as reformas administrativas no setor público (BRESSER-PEREIRA e SPINK, 1998), não se atribui somente mudanças na legislação, sistemas, e organizações, mas também se investe na criação de condições para o desenvolvimento das pessoas que conduzirão e realizarão as reformas (OLIVEIRA FILHO, 2012).

Desta forma, a gestão de pessoas na esfera pública possui um papel estratégico para alinhar os objetivos da organização com as políticas de desenvolvimento de pessoas (GEMELLI; FILIPPIM, 2010; GODOY, 2014). Alinhar aqui representa perceber, diagnosticar, pesquisar as necessidades de capacitação para o alcance dos objetivos organizacionais, e conhecer quais capacidades os servidores já possuem e onde eles podem utilizá-las da melhor forma. O mapeamento de competências auxilia nesta escolha direcionada porque norteia assunto a capacitar com a orientação profissional, a avaliação de desempenho e o planejamento de carreira (BRANDÃO; BAHRY, 2005).

Constitui também um desafio para as instituições públicas assumirem um papel qualificante, apoiando as iniciativas de desenvolvimento profissional, criando um ambiente que seja propício à aprendizagem e oferecer aos servidores oportunidades reais de crescimento na carreira (BRANDÃO; BAHRY, 2005). 
Portanto, o setor que trata de gestão de pessoas na esfera pública federal não pode mais ser visto apenas como um setor que contrata ou exonera pessoas, e sim como um setor que constantemente busque aprimorar a qualificação e a capacitação dos seus servidores (LIMA, 2017)

E é necessária a participação de toda a instituição para a capacitação estratégica do servidor, pois envolve planejamento institucional, financiamento, parcerias, interesse do servidor, motivação, sua visão de futuro e senso de dever para com o país. O serviço público brasileiro necessita hoje de servidores capazes de agir, tomar decisões e melhorar a gestão pública. Necessita de futuros líderes entre os atuais servidores, com dedicação e amor ao serviço, ainda que a gratificação financeira seja limitada (AMARAL, 2006), ainda que com as limitações específicas em recrutamento dos servidores e seus planos de carreira, e as restrições que os políticos podem impor (BACON, 1999).

A questão da motivação para o trabalho nos serviços públicos é ao mesmo tempo essencial e audaciosa. Essencial pois em países industrializados os serviços públicos estão presentes em diversos setores como saúde, educação, serviços sociais e cultura. E audaciosa porque uma parcela da população crê que os serviços públicos estão associados à imagem de servidores poucos inclinados a trabalhar e mais preocupados com suas vantagens e seus privilégios (CHANLAT, 2002).

E ainda, após a ascensão do gerencialismo na administração pública, o setor tem apresentado carga de trabalho considerável, grau mais ou menos elevado de autonomia, reconhecimento e amparo social. Tais fatores fazem com que um trabalho seja ou não interessante, e as consequências e a intensidade desses fatores não serão as mesmas para as pessoas, refletindo na motivação para o trabalho (CHANLAT, 2002).

Portanto, valorizar o servidor é necessário, pois significa estimular sua criatividade e capacidade empreendedora, ressaltando o espírito público de sua missão e seu comportamento ético (OLIVEIRA FILHO, 2012). O foco da motivação não deve estar mais só no indivíduo, mas na interação indivíduo e organização, apesar de esta encontrar-se em constante mudança provocada pelo ambiente. A organização pública deve estar atenta e alinhada às necessidades do ambiente: funcionários, governo, sociedade e mundo (FLEURY; FLEURY, 2001). Deve estimular a relação do servidor com sua contribuição no setor público (LIMA, 2017). Especificamente no contexto desta pesquisa, estimular o sentimento de poder contribuir para a 
educação superior brasileira, cabendo à gestão, manter alimentada a importância deste motivo no servidor, respeitando a individualidade de cada um deles (LIMA, 2017).

A individualidade na capacitação pode respeitada quando oferecidas nas diversificadas áreas do conhecimento e modalidades - respeitando sempre a legislação, a missão e os objetivos organizacionais (SILVA e SILVA, 2018). Os autores Brandão e Bahry (2005), ao assessorarem o mapeamento de competências em um órgão público, verificaram que, se o processo de desenvolvimento dos servidores ficasse limitado a ações formais de capacitação e suas limitações orçamentárias, dificilmente a gestão de pessoal conseguiria concretizar a visão de futuro da instituição.

É preciso que a liderança reconheça a necessidade de dedicar mais tempo e atenção ao desenvolvimento das capacidades dos servidores (BACON, 1999; SILVA e SILVA, 2018). E isto ultrapassa a participação em cursos de capacitação, e inclui o monitoramento da aprendizagem durante o trabalho, a ampliação e diversificação de tarefas, a rotatividade de funções e a participação em projetos especiais. (LIMA, 2017). A instituição deve aproveitar todas as oportunidades de oferecer possibilidades de desenvolvimento prático da liderança aos servidores, por exemplo, com o objetivo de aumentar o número de dirigentes competentes nas instituições públicas (BACON, 1999).

E sendo estratégica, os resultados da capacitação devem ser observados e medidos; verificando-se resultados da aprendizagem que nem sempre são concretos. São principalmente, um comportamento que reflete o desenvolvimento daquela competência, pois os conhecimentos não adquirem status de competência a não ser que sejam comunicados e utilizados (FLEURY; FLEURY, 2001).

Por último, o desenvolvimento dos servidores no contexto das IFES torna-se estratégico em um contexto de profundas mudanças estruturais advindas do processo Reestruturação e Expansão das Universidades Federais (REUNI) instituído pelo Decreto 6.096/2007. Esta reestruturação teve como objetivos a criação de condições para a ampliação do acesso e permanência na educação superior no nível de graduação, o melhor aproveitamento da estrutura física e de recursos humanos, a elevação gradual da taxa de conclusão dos cursos de graduação presenciais. (BRASIL, 2007)

O REUNI permitiu que fossem realizados mais concursos para admissão de professores e técnicos administrativos, mas não na quantidade e prazos acordados neste programa de expansão (PREDES, 2015). Ou seja, foram aumentadas as vagas nos cursos de graduação e o quantitativo de professores e técnicos administrativos não aumentou 
proporcionalmente conforme acordado, aumentando a sobrecarga de trabalho (RODRIGUES, 2017), tornando a capacitação e qualificação ações estratégicas para o cumprimento dos objetivos organizacionais.

\section{Procedimentos metodológicos para o diagnóstico e proposta de intervenção}

\subsection{Procedimentos Metodológicos para o Diagnóstico}

A ação conjunta da Coordenação de Desenvolvimento de Pessoas (CODEP), de seus gestores e da Reitoria tinha três objetivos: (a) a intenção de desenvolver estrategicamente as competências dos servidores técnico administrativos, permitindo assim, atingir a missão e visão da Universidade; (b) o retorno desta capacitação em trabalho eficiente e eficaz aproveitando melhor o recurso público; e (c) a valorização do conhecimento e figura do servidor técnico administrativo.

Tais desafios deveriam ser cumpridos para aprimorar o aproveitamento do orçamento para a capacitação, capacitando estrategicamente.

Então primeiramente a CODEP avaliou as ações de capacitação executadas em 2017 para identificar o que precisaria ser aprimorado no exercício de 2018, avaliando os valores gastos com capacitação, percentual de servidores capacitados e setores aos quais pertenciam para verificar o quanto a capacitação estava se estendendo na Universidade - apresentado na segunda seção deste relato.

Posteriormente foi realizada uma organização interna de trabalho na CODEP, realizando-se ajustes de quantidade e qualidade de sua equipe; nova divisão de tarefas; metodologia e mapeamento de processos internos; melhoramento da capacidade estrutural para execução de cursos; elaboração de fluxogramas para auxiliar as solicitações de capacitação; formação de equipes multidisciplinares de avaliação de solicitação de cursos assegurando o acesso dos servidores à capacitação de acordo com a área que atuava e em conformidade com a legislação vigente; parcerias com outros setores da Universidade para realização de eventos; formação de servidores multiplicadores para aprendizagem em cursos externos e posterior formação de turmas internas; formação de banco de dados de instrutores de cursos, selecionados por edital público. 
Após isto, foi iniciado um diagnóstico estratégico das necessidades de capacitação alicerçando-se em quatro pilares: a visão estratégica da alta gestão; o acompanhamento da elaboração do Plano de Desenvolvimento Institucional (PDI) da Universidade; a visão especialista da CODEP; e as demandas dos servidores e suas chefias:

i. Visão estratégica da alta gestão: as necessidades de capacitação foram manifestadas pela alta gestão através de reuniões com os gestores da Universidade e da área de Recursos Humanos, e em reuniões da Comissão Orçamentária 2018. As informações extraídas eram principalmente a necessidade de técnico administrativos conhecedores das leis, conhecedores e racionalizadores dos fluxos de trabalho, comprometidos com a Universidade e o serviço público federal. Foi evidente a necessidade de otimização do orçamento público em tempos ausência de vagas e redistribuição da força de trabalho.

ii. $\quad$ O acompanhamento da elaboração do PDI: as necessidades de capacitação foram evidenciadas nas participações das reuniões de discussão e elaboração do PDI. Assim como o item anterior, as situações almejadas foram transformadas em temas de capacitação.

iii. A visão especialista da CODEP: a equipe CODEP à época era formada por especialistas da área de Recursos Humanos, Administração e Análise de Dados, graduados e pós-graduados nas áreas, além de possuírem experiência de trabalho no serviço público. A equipe foi autorizada a participar de reuniões de gestão - Diretores, Conselheiros, Coordenadores e Pró-Reitores - nas quais eram expostos problemas envolvendo técnicos administrativos e gestores, problemas com ao atendimento e ao desempenho de servidores. Desta forma, a visão da equipe e sua experiência com relação a capacitação possibilitaram a inserção e agrupamento de temas de capacitação.

iv. As demandas dos servidores e suas chefias: as necessidades de capacitação foram colhidas por meio de dois formulários distribuídos pela Universidade via Memorando Eletrônico e papel impresso. O primeiro formulário objetivava captar informações mais genéricas, tais como, número de servidores lotados no setor, servidores capacitados em 2017 e entre outras. O segundo formulário visava levantar as necessidades de capacitação, estruturado em áreas temáticas: gestão de pessoas, gestão estratégica, gestão de processos, liderança, comunicação, finanças, compras e serviços, gestão de documentos, informática e tecnologia da informação, patrimônio e logística, procedimentos e segurança, secretariado, assessoria e eventos. Como ocorrera em anos anteriores, a quantidade das respostas aos formulários foi aquém do desejado, correspondendo a $16 \%$ do quadro de servidores técnicos. 
Entretanto, os quatro pilares da pesquisa permitiram a diversificação das formas de diagnóstico validando a pesquisa.

Após estas ações a CODEP iniciou um trabalho de delimitação dos ambientes organizacionais de atuação do servidor no âmbito das IFES, definidos no Decreto 5.824/2006 para enquadramento das áreas de capacitação, e o quantitativo de servidores técnico administrativos presentes nestas áreas. Os ambientes definidos foram (i) Administrativo, (ii) Infra-estrutura, (iii) Ciências Humanas, Jurídicas e Econômicas, (iv) Ciências Biológicas, (v) Ciências Exatas e da Natureza, (vi) Ciências da Saúde, (vii) Agropecuário, (viii) Informação, (xix) Artes, Comunicação e Difusão, e (x) Marítimo, Fluvial e Lacustre (BRASIL, 2006).

A Universidade em questão, por sua natureza e cursos, contemplou todos estes ambientes, tendo sua estrutura e quadro funcional com atuação em vários destes ambientes organizacionais ao mesmo tempo.

Tabela 2

Quantitativo de servidores e atuação nos ambientes. Extraído de PAC-2018 UFRRJ.

\begin{tabular}{|c|c|c|c|c|c|c|c|c|c|c|c|c|}
\hline & & & & abie & ntes & & & & & & & \\
\hline Estrutura Universitária & $\begin{array}{l}\text { Docent } \\
\text { es }\end{array}$ & $\begin{array}{l}\text { Técnic } \\
\text { os }\end{array}$ & 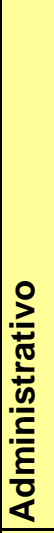 & 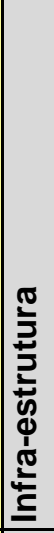 & 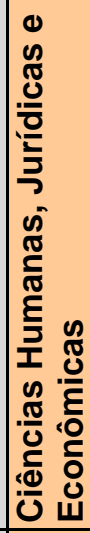 & 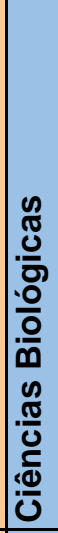 & 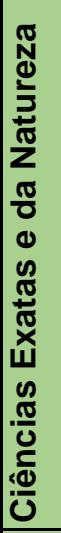 & 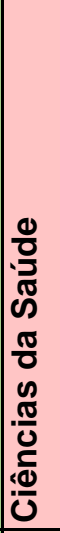 & 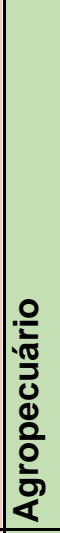 & 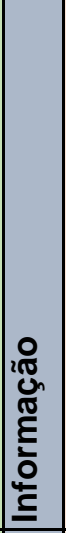 & 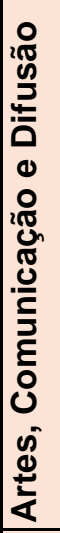 & 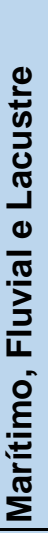 \\
\hline ÓRGAOS COLEGIADOS & & 1 & $\mathrm{X}$ & $\mathrm{X}$ & $\mathrm{X}$ & $\mathrm{X}$ & $\mathrm{X}$ & $\mathrm{X}$ & $\mathrm{X}$ & $\mathrm{X}$ & $\mathrm{X}$ & $\mathrm{X}$ \\
\hline REITORIA & & & & & & & & & & & & \\
\hline ASSESSORIAS & 6 & 4 & $\mathrm{X}$ & $\mathrm{X}$ & $\mathrm{X}$ & $x$ & $\mathrm{X}$ & $\mathrm{X}$ & $\mathrm{X}$ & $\mathrm{X}$ & $\mathrm{X}$ & $\mathrm{X}$ \\
\hline AUDITORIA INTERNA & & 2 & $\mathrm{X}$ & $\mathrm{X}$ & $\mathrm{X}$ & $\mathrm{X}$ & $\mathrm{X}$ & $\mathrm{X}$ & $\mathrm{X}$ & $\mathrm{X}$ & $\mathrm{X}$ & $\mathrm{X}$ \\
\hline BIBLIOTECA CENTRAL & & $\begin{array}{l}4 \\
3\end{array}$ & $\mathrm{X}$ & & & & & & & $\mathrm{X}$ & & \\
\hline $\begin{array}{l}\text { CENTRO DE ATENÇÃO } \\
\text { INTEGRAL À CRIANÇA }\end{array}$ & 1 & 8 & $\mathrm{X}$ & & $\mathrm{X}$ & & & & & $\mathrm{X}$ & & \\
\hline COLEGIO TECNICO & 59 & $\begin{array}{l}3 \\
0\end{array}$ & $\mathrm{X}$ & $\mathrm{X}$ & $\mathrm{X}$ & $\mathrm{X}$ & $\mathrm{X}$ & & $\mathrm{X}$ & $\mathrm{X}$ & & \\
\hline COORDENAÇÕES/REITORIA & & $\begin{array}{l}2 \\
9\end{array}$ & $\mathrm{X}$ & & $\mathrm{X}$ & & & & $\mathrm{X}$ & $\mathrm{X}$ & $\mathrm{X}$ & \\
\hline GABINETE DA REITORIA & 2 & $\begin{array}{l}1 \\
6\end{array}$ & $\mathrm{X}$ & $\mathrm{X}$ & & & & & & & & \\
\hline
\end{tabular}




\begin{tabular}{|c|c|c|c|c|c|c|c|c|c|c|c|c|}
\hline $\begin{array}{l}\text { CAMPOS DOS GOYTACAZES } \\
\text { (DIREÇÃO e CAMPUS) }\end{array}$ & & $\begin{array}{l}5 \\
2\end{array}$ & $\mathrm{X}$ & $\mathrm{X}$ & & & $x$ & & $\mathrm{X}$ & $\bar{X}$ & & \\
\hline INSTITUTO DE AGRONOMIA & 69 & $\begin{array}{l}4 \\
5\end{array}$ & $\mathrm{X}$ & & & & $x$ & & $x$ & & & \\
\hline $\begin{array}{l}\text { INSTITUTO DE CIÊNCIAS } \\
\text { BIOLÓGICAS E DA SAÚDE }\end{array}$ & 97 & $\begin{array}{l}5 \\
2 \\
\end{array}$ & $\mathrm{X}$ & $\mathrm{X}$ & & $x$ & $\mathrm{x}$ & & & & & $\mathrm{x}$ \\
\hline $\begin{array}{l}\text { INSTITUTO DE CIÊNCIAS } \\
\text { EXATAS }\end{array}$ & 133 & $\begin{array}{l}4 \\
8\end{array}$ & $\mathrm{X}$ & $\mathrm{X}$ & & & $x$ & & & & & \\
\hline $\begin{array}{l}\text { INSTITUTO DE CIÊNCIAS } \\
\text { HUMANAS E SOCIAIS }\end{array}$ & 163 & $\begin{array}{l}3 \\
5\end{array}$ & $\mathrm{X}$ & $\mathrm{X}$ & $x$ & & & & & & $x$ & \\
\hline $\begin{array}{l}\text { INSTITUTO DE CIÊNCIAS } \\
\text { SOCIAIS APLICADAS }\end{array}$ & 114 & $\begin{array}{l}1 \\
7\end{array}$ & $\mathrm{X}$ & $\mathrm{X}$ & $\mathrm{x}$ & & & & & & & \\
\hline INSTITUTO DE EDUCAÇÃO & 87 & $\begin{array}{l}2 \\
2\end{array}$ & $\mathrm{X}$ & $\mathrm{X}$ & $x$ & & & & & & & \\
\hline INSTITUTO DE FLORESTAS & 37 & $\begin{array}{l}1 \\
9\end{array}$ & $\mathrm{X}$ & $\mathrm{X}$ & & & $x$ & & $x$ & & & \\
\hline INSTITUTO DE TECNOLOGIA & 100 & $\begin{array}{l}4 \\
7\end{array}$ & $\mathrm{X}$ & $\mathrm{X}$ & & & $x$ & $\mathrm{x}$ & $\mathrm{x}$ & $\mathrm{x}$ & $\mathrm{x}$ & \\
\hline $\begin{array}{l}\text { INSTITUTO DE VETERINÁRIA (e } \\
\text { HOSPITAL) }\end{array}$ & 65 & $\begin{array}{l}6 \\
2\end{array}$ & $\mathrm{X}$ & $\mathrm{X}$ & & $x$ & $x$ & $\mathrm{x}$ & $x$ & & & $x$ \\
\hline INSTITUTO DE ZOOTECNIA & 35 & $\begin{array}{l}1 \\
8\end{array}$ & $\mathrm{x}$ & $\mathrm{x}$ & & $\mathrm{x}$ & & $\mathrm{x}$ & $\mathrm{x}$ & & & $x$ \\
\hline $\begin{array}{l}\text { INSTITUTO MULTIDISCIPLINAR } \\
\text { (Instituto e } \\
\text { Campus) }\end{array}$ & 164 & $\begin{array}{l}6 \\
2\end{array}$ & $\mathrm{x}$ & $\mathrm{x}$ & $x$ & & $\mathrm{x}$ & & & $\mathrm{x}$ & & \\
\hline $\begin{array}{l}\text { INSTITUTO TRÊS RIOS (Instituto e } \\
\text { Campus) }\end{array}$ & 74 & $\begin{array}{l}2 \\
7\end{array}$ & $\mathrm{X}$ & $\mathrm{X}$ & $\mathrm{X}$ & $\mathrm{X}$ & $x$ & & & $\mathrm{X}$ & & $\mathrm{x}$ \\
\hline $\begin{array}{l}\text { PREFEITURA UNIVERSITÁRIA } \\
\text { (Seropédica) }\end{array}$ & & 143 & $\mathrm{X}$ & $\mathrm{X}$ & & & & & & & & \\
\hline PROCURADORIA GERAL & & 2 & $\mathrm{X}$ & $\mathrm{X}$ & $\mathrm{X}$ & $x$ & $\mathrm{X}$ & $X$ & $\mathrm{X}$ & $\mathrm{X}$ & $\mathrm{X}$ & $\mathrm{x}$ \\
\hline $\begin{array}{l}\text { PRÓ-REITORIA DE ASSUNTOS } \\
\text { ADMINISTRATIVOS }\end{array}$ & 1 & 135 & $\mathrm{X}$ & $\mathrm{X}$ & & & & $\mathrm{x}$ & & & & \\
\hline $\begin{array}{l}\text { PRÓ-REITORIA DE ASSUNTOS } \\
\text { ESTUDANTIS }\end{array}$ & 2 & $\begin{array}{l}5 \\
6 \\
\end{array}$ & $\mathrm{X}$ & $\mathrm{X}$ & & & & & & & & \\
\hline $\begin{array}{l}\text { PRÓ-REITORIA DE ASSUNTOS } \\
\text { FINANCEIROS }\end{array}$ & 1 & $\begin{array}{l}7 \\
5\end{array}$ & $\mathrm{X}$ & $\mathrm{X}$ & & & & & & & & \\
\hline PRÓ-REITORIA DE EXTENSÃO & 2 & $\begin{array}{l}4 \\
5\end{array}$ & $\mathrm{X}$ & $\mathrm{X}$ & & & & & & & $\mathrm{x}$ & \\
\hline PRÓ-REITORIA DE GRADUAÇÃO & 4 & $\begin{array}{l}3 \\
6\end{array}$ & $\mathrm{X}$ & $\mathrm{X}$ & $x$ & $\mathrm{x}$ & $x$ & $\mathrm{x}$ & $\mathrm{x}$ & $\mathrm{x}$ & $\mathrm{x}$ & $\mathrm{x}$ \\
\hline $\begin{array}{l}\text { PRÓ-REITORIA DE PESQUISA E } \\
\text { PÓS-GRADUAÇÃO }\end{array}$ & 4 & $\begin{array}{l}1 \\
8\end{array}$ & $\mathrm{X}$ & $\mathrm{X}$ & $x$ & $\mathrm{x}$ & $x$ & $\mathrm{x}$ & $\mathrm{x}$ & $\mathrm{x}$ & $x$ & $x$ \\
\hline $\begin{array}{l}\text { PRÓ-REITORIA DE PLANEJ. } \\
\text { AVAL. E DESENV.INST. }\end{array}$ & 1 & $\begin{array}{l}5 \\
1\end{array}$ & $\mathrm{X}$ & $\mathrm{X}$ & & & & & & $\mathrm{x}$ & & \\
\hline
\end{tabular}

Após a divisão da estrutura nos ambientes organizacionais, todo o diagnóstico de capacitação foi assim agrupado, possibilitando desenvolver (a) Programas Específicos de Capacitação; (b) Trilhas de Capacitação para Especialistas e Futuros Gestores; e (c) Cursos Avulsos, que serão aqui apresentados na Proposta de Intervenção.

\subsection{Proposta de Intervenção}


Os resultados do estudo das necessidades de capacitação foram sintetizados e apresentados ao Conselho Universitário e à Comissão Orçamentária sob a forma do Plano Anual de Capacitação 2018 (PAC-2018) com nova proposta orçamentária, direcionando e organizando as ações de capacitação de forma que contribuíssem para o desenvolvimento e o aperfeiçoamento de competências institucionais e individuais dos técnico administrativos, buscando potencializar a excelência das atividades por eles prestadas para o atingimento das metas delineadas no PDI.

Foram apresentados como objetivos do PAC-2018:

1) Organizar a capacitação por programas temáticos e trilhas de capacitação;

2) Ampliar a oferta de cursos de capacitação no exercício de 2018 por meio da diversificação das ações de capacitação em fóruns, cursos externos, internos e incompany;

3) Desenvolver de forma continuada as competências dos servidores por meio de ações e estratégias de aprendizagem que favoreçam o desenvolvimento institucional mesmo com quadro de servidores aquém do necessário para a Instituição, por meio do aprimoramento das habilidades gerenciais, organizacionais, técnicas e interpessoais dos servidores;

4) Promover ações de capacitação direcionadas ao desenvolvimento individual e profissional dos gestores.

Foram apresentados Programas Específicos de Capacitação, Trilhas de Capacitação e Cursos Avulsos.

Os Programas específicos de Capacitação foram elaborados a partir da alta demanda por capacitação em áreas gerais, adicionados à visão da alta gestão e da CODEP, extraídos dos dados coletados e das percepções das reuniões e observações.

Foram organizados os Programas de Capacitação para Gestores - que incluíam desde orçamento público e licitação, até gestão, ética, e relacionamento interpessoal; de Valorização do Técnico Administrativo - incluindo desde temas operacionais até relacionamento e conflitos; e de Preparação do Técnico para a Pós-Graduação Stricto Sensu.

As Trilhas de Capacitação tiveram como objetivo nortear a capacitação do servidor na área em que ele se encontra inserido profissionalmente. Refletiu-se que nem todos os servidores serão gestores, então as trilhas possibilitam criar um Banco de Dados de servidores capacitados técnica e emocionalmente para exercer futuramente, cargos de gestão, aprofundar o conhecimento técnico, assessorar os gestores da Universidade, e não desviar o servidor de 
sua área de atuação - a não ser que o desenvolvimento interdisciplinar seja um diferencial profissionalmente.

A Trilhas construídas com cursos próprios foram as de (i) Gestão Financeira, Compra se Contratos, (ii) Gestão de Pessoas, (iii) Gestão Estratégica, (iv) Gestão Patrimonial e Infraestrutura, (v) Gestão Acadêmica, (vi) Informação, (vii) Artes, Comunicação e Difusão, (viii) Capacitação Técnica das Ciências Biológicas, (xix) Capacitação Técnica das Ciências Extas e da Natureza, (x) Capacitação Técnica das Ciências da Saúde, (xi) Capacitação Técnica das Ciências Humanas, Jurídicas e Econômicas, (xii) Capacitação Técnica das Ciências Agropecuárias, (xiii) Capacitação Técnica do Ambiente Marítimo, Fluvial e Lacustre.

Os cursos avulsos foram aqueles que abrangiam várias áreas e foram amplamente solicitados pelos servidores, como libras, linguagens de programação, preparação para aposentadoria, Processo Administrativo Disciplinar, Redação Oficial e Técnica, Sistema de Concessão de Diárias e Passagens (SCDP), editores de texto e bancos de dados, programas de criação visual, planilhas eletrônicas, gerenciamento de projetos, e idiomas.

Além de tais ações e aproveitando o momento de evidência da capacitação e qualificação do servidor técnico administrativo, a Pró-Reitoria de Administração negociou junto aos cursos de Pós-Graduação Stricto Sensu, vagas especiais para os servidores técnicos da Universidade, os quais participariam de processo seletivo com o mesmo rigor que os outros candidatos, com bolsas ofertadas aos Programas de Pós-Graduação para gastos com a qualificação dos alunos servidores - tudo incluído no orçamento da Ação 4572.

\subsection{Orçamento Proposto}

Com base no diagnóstico de capacitação, multiplicando valores dos cursos, estimando gastos e quantidades de servidores existentes para acesso de todos às ações de capacitação, o orçamento da Ação 4572 para o ano de 2018, após algumas alterações, ajustes, contingenciamentos orçamentários e remanejamentos entre outras Ações dentro da própria Universidade ficou assim distribuído:

\section{Tabela 3}

Orçamento Proposto. Elaboração própria. 


\begin{tabular}{|c|c|c|}
\hline Identificação & Valor (R\$) & Fixação em Natureza de \\
Despesamento 2018 & $\mathbf{9 2 4 . 7 6 4 , 0 0}$ & 33.90 .39 \\
\hline $\begin{array}{c}\text { Onscrições em Cursos Externos (PJ) } \\
\text { Cursos Internos e Palestras (Pagamento } \\
\text { com GECC) }\end{array}$ & $273.631,42$ & 33.90 .36 \\
\hline Diárias no país & $203.567,56$ & 33.90 .14 \\
\hline Passagens no país & $121.341,09$ & 33.90 .33 \\
\hline $\begin{array}{c}\text { Auxilio Financeiro a estudantes (bolsistas } \\
\text { para cursos de idiomas) }\end{array}$ & $77.350,00$ & 33.90 .18 \\
\hline GECC 2017 a pagar (dívida de 2017) & $28.323,93$ & 33.90 .92 \\
\hline $\begin{array}{c}\text { Auxílio financeiro ao Pesquisador (para } \\
\text { eventos no exterior) }\end{array}$ & $15.000,00$ & 33.90 .20 \\
\hline $\begin{array}{c}\text { Inscrições em Cursos Externos (PJ) - } \\
\text { operação Intra Orçamentárias (Escolas de } \\
\text { Governo) }\end{array}$ & $5.050,00$ & 33.91 .33 \\
\hline
\end{tabular}

Apesar da proposta orçamentária quadruplicar o orçamento para a Ação 4572, após várias reuniões orçamentárias com os Conselheiros, a proposta foi aceita devido a capacidade argumentativa, à seriedade da pesquisa empírica e às justificativas estratégicas. Mas é importante ressaltar que não foram solicitados por isso, mais valores ao governo federal: ocorreu um remanejamento interno do dinheiro público, ou seja, a Universidade trabalhou com o que já possuía de previsão orçamentária. Para aumentar o orçamento da capacitação foi retirado orçamento de outras Ações internas da Universidade e remanejados para a Ação 4572, pois aquelas demonstravam utilização com sobras e menor controle de gastos. Tal atitude dos Conselheiros foi vista como valorização do servidor técnico administrativo, que será um dos assuntos comentados na análise dos resultados

\section{Resultados da intervenção e sua análise}

\subsection{Da adequação estratégica}

NA pesquisa empírica foi observado que o aumento da complexidade do trabalho (PEREIRA e SILVA, 2011) e a sobrecarga (RODRIGUES, 2017) estavam presentes na Universidade por sua adesão ao REUNI (PREDES, 2015), pois a quantidade de técnicos administrativos não cresceu proporcionalmente conforme o aumento da oferta de vagas nos cursos de graduação. Estavam presentes também devido à grande quantidade de servidores a aposentar-se e alguns, não se adequando ao ritmo acelerado do novo serviço público. 
Desta forma, pôde-se oportunizar pela primeira vez na Universidade um estudo complexo sobre as necessidades de capacitação com um olhar de aproveitamento dos gastos para capacitação estratégica e melhoria dos serviços públicos, conforme citado em Gemelli e Filippim (2010); Pereira e Silva (2011); Godoy (2014).

A metodologia utilizada na identificação das necessidades de capacitação não chegou a um mapeamento de competências completo no formato de Brandão e Bahry (2005), pois foi realizada a pesquisa de demandas, mas não houve tempo hábil de verificar o que a Universidade já possuía de competências dos seus servidores. Não oficialmente. Muitas chefias e os próprios servidores, ao expor suas necessidades já contavam com isto.

Entretanto, a identificação de necessidades foi estratégica pois contou com os quatro pilares, iniciando pela visão da alta gestão da Instituição, passando pela visão e experiência dos elaboradores do PDI, pela visão da CODEP e ouvindo as demandas dos servidores e suas chefias. Esta participação da direção e integração das áreas institucionais é citada por Amaral (2006) que defende a participação de toda a instituição para a capacitação estratégica, e Pereira e Silva (2011) quando lembram que a gestão de IFES mescla aspectos burocráticos, políticos e colegiados.

O reconhecimento, participação e apoio da alta gestão em todo o processo foi gratificante e importante para a legitimidade e autoridade da CODEP, pois, conforme Bacon (1999) e Silva e Silva (2018) afirmaram, é importante que a liderança reconheça a necessidade de dedicarem mais tempo e atenção ao desenvolvimento das capacidades dos servidores. Isto criou uma atmosfera da importância do desenvolvimento dos servidores técnicos administrativos (OLIVEIRA FILHO, 2012) e criação de condições de capacitação, mesmo que a contragosto de algumas chefias.

A Instituição assumiu ainda, um papel incentivador e qualificante (BRANDÃO; BAHRY, 2005) ao reservar parte do orçamento para bolsas ofertadas ao Programas de PósGraduação, para gastos com a qualificação dos alunos servidores, e reserva de vagas para eles - que, apesar do rigor no processo seletivo e tratamento acadêmico, estimulou a presença dos técnicos administrativos em Programas Stricto Sensu Profissionais e Acadêmicos. Esta ação foi submetida e aprovada pelo Conselho Universitário, e até o final de 2018, quinze Programas Pós-Graduação aderiram a este Programa de Qualificação Institucional (PQI), sendo ofertadas 41 vagas de mestrado e 16 para doutorado especialmente para os servidores técnicos administrativos. 
Entretanto, apesar de tais ganhos funcionais, institucionais e pessoais, ainda existiam opiniões contrárias ao uso do dinheiro público com capacitação adequada aos objetivos organizacionais: havia um grupo de servidores que ia para as reuniões de colegiados defender que os gastos com capacitação deveriam ocorrer a critério de cada servidor, sem adequação de áreas e objetivos organizacionais. Entendemos que, apesar da necessidade de se respeitar a individualidade do servidor, o dinheiro público deve ser utilizado com ética e respeito ao contribuinte. Vimos neste momento, a fala de Chanlat (2002), ao citar que muitos servidores são vistos como pessoas mais preocupadas com suas vantagens e seus privilégios.

Mesmo assim, os trabalhos seguiram em frente e foram oferecidas ações de capacitação nas diversificadas áreas do conhecimento e modalidades de capacitação (SILVA e SILVA, 2018), objetivou-se criar nova cultura de capacitação, ressaltando o espírito público de sua missão (OLIVEIRA FILHO, 2012); estimulando a relação do servidor com sua contribuição no setor público (LIMA, 2017); ampliando a diversificação de tarefas e a participação em projetos especiais (LIMA, 2011) como a pioneira iniciativa da criação dos grupos de estudo e trabalho para adequação da Universidade à Instrução Normativa 01/2018 iii .

Até o momento da escrita deste relato não houve oportunidade de praticar a rotatividade de funções citada por LIMA (2017) nem de mensuração de resultados em medidas concretas de produtividade citada por Fleury e Fleury (2001), apesar do aumento expressivo de participações e melhoria na efetividade dos gastos, conforme será comentado no final desta seção.

Quanto a diversificação das formas de capacitação (SILVA e SILVA, 2018) foram oferecidos cursos internos, externos, eventos e fóruns para o desenvolvimento dos servidores, conforme os assuntos diagnosticados como necessários e adequados aos objetivos organizacionais. Os cursos internos são os promovidos dentro da Universidade, com a ministração de instrutores que foram selecionados por editais e pagamento por Gratificação por Encargos de Cursos e Concursos - GECC. Esta modalidade capacita um número maior de servidores pois é constituído de turmas. Os cursos externos são cursos oferecidos por Escolas de Governo ou Instituições Privadas e capacita individualmente o servidor. Sua pertinência deve ser avaliada por Comissão e as inscrições, pagas por empenho com processo legalmente instruído, com diárias e passagens pagas via sistema SCDP. Os eventos e fóruns de capacitação e discussão são organizados internamente pela CODEP ou outros setores em 
parceria com a Coordenação. Os palestrantes são pagos por GECC e escolhidos mediante Comissão ou, para áreas específicas e técnicas, escolhidos por profissionais de área.

Além das ações de capacitação, a CODEP acumulou a função, no ano de 2018, do controle de afastamento de servidores docentes e técnico administrativos em conformidade com a legislação, trazendo assim, mais tarefas, mas as ações foram cumpridas.

\subsection{Da adequação legal}

A política de capacitação e desenvolvimento dos servidores técnicos apresentadas no PAC-2018 foi vinculada ao PDI da Universidade, e em conformidade com as Leis $\mathrm{n}^{\circ}$ 8.112/1990, Lei 11.091/2005 e o Decreto 5.507/2006. E ainda, todos os procedimentos de gastos da Ação 472 foram revistos e adequados à Lei 8.666/93.

É importante ressaltar que o PAC já existia na Universidade, mas foi a primeira vez que seu diagnóstico foi realizado na forma estratégica, e isto em conformidade com a exigência legal do Decreto 5.707/2006, justificando-se por ser um instrumento de planejamento para nortear as ações de capacitações necessárias para o desenvolvimento dos servidores técnicos, de forma continuada.

\subsection{Da construção da proposta orçamentária e seus resultados numéricos}

Após o diagnóstico de capacitação e os cálculos dos respectivos gastos, foi elaborada proposta orçamentária e discutida em várias reuniões da Comissão Orçamentária, apresentada pelo Reitor e submetida aos órgãos colegiados superiores. Tal forma de elaboração corrobora com a Lei de Diretrizes e Bases da Educação (Brasil, 1996) e com o Estatuto e Regimento da Universidade.

Durante a elaboração da proposta orçamentária a CODEP aprendeu as normas de orçamento público através da interação com as áreas financeiras da Instituição. Tal parceria proporcionou maior segurança durante todo o processo de elaboração da proposta, utilização e controle dos gastos da Ação 4572, comprovando que a integração das áreas institucionais é importante para a gestão de pessoas e para a para a capacitação estratégica (AMARAL, 2006).

$\mathrm{Na}$ proposta orçamentária escrita foram classificadas e organizadas as despesas de acordo com sua Função, Subfunção, Programa e Ação (GIACOMONI, 2007; SOF, 2017) e em março do ano de 2019 foi lançado o Relatório de Gestão da CODEP no portal da 
Instituição, revelando publicamente o resultado dos gastos de capacitação e a execução das atividades.

Observou-se que após esta intervenção, a Instituição aumentou expressivamente o número de capacitações internas e externas quando comparado ao ano anterior em cinco e quatro vezes mais, respectivamente, com o triplo do orçamento.

Do valor total fixado na Ação 4572, foram gastos $\mathrm{R} \$$ 737.7.61. O saldo da diferença entre o orçado e o executado foi remanejado para outras ações, por solicitação da instituição, conforme especificado no tab. 4.

\section{Tabela 4}

Distribuição e execução orçamentária por elemento de despesa. Elaboração própria.

\begin{tabular}{|c|c|c|c|c|}
\hline Identificação & Fixação em Natureza & Fixados R\$ & Valores executados & Saldo \\
Orçamento 2018 & & $\mathbf{9 2 4 . 7 6 4 , 0 0}$ & (liquidados e pagos) R\$ & \\
\hline de Despesa & 33.90 .39 & $273.631,42$ & $273.631,42$ & 0,00 \\
\hline $\begin{array}{c}\text { Inscrições em Cursos Externos (PJ) } \\
\text { (Pagamento com GECC) }\end{array}$ & 33.90 .36 & $203.567,56$ & $116.236,19$ & $87.331,37$ \\
\hline Diárias no país & 33.90 .14 & $200.500,00$ & $194.448,04$ & $6.051,96$ \\
\hline Passagens no país & 33.90 .33 & $121.341,09$ & $118.916,10$ & $2.424,99$ \\
\hline $\begin{array}{c}\text { Auxilio Financeiro a estudantes } \\
\text { (bolsistas para cursos de idiomas) }\end{array}$ & 33.90 .18 & $77.350,00$ & 0,00 & $77.350,00$ \\
\hline GECC 2017 a pagar (dívida de 2017) & 33.90 .92 & $28.323,93$ & $28.323,93$ & 0,00 \\
\hline $\begin{array}{c}\text { Auxílio financeiro ao Pesquisador } \\
\text { (para eventos no exterior) }\end{array}$ & 33.90 .20 & $15.000,00$ & $1.099,93$ & $13.900,07$ \\
\hline $\begin{array}{c}\text { Inscrições em Cursos Externos (PJ) - } \\
\text { operação Intra Orçamentárias } \\
\text { (Escolas de Governo) }\end{array}$ & 33.91 .33 & $5.050,00$ & $5.050,00$ & 0,00 \\
\hline
\end{tabular}

$187.058,39$

A capacitação interna foi promovida e subdividida em cursos e eventos, e seu pagamento foi realizado com base na tabela oficial de GECC do serviço público federal, por hora de trabalho. Em 2018, a CODEP realizou 42 ações que totalizou 1421 capacitações realizadas internamente, proporcionando um público médio de 34 pessoas por ação.

Os cursos externos foram pagos por empenho, em processos legalmente instruídos, com diárias e passagens pagas via sistema SCDP. Em 2018, a CODEP realizou 69 capacitações externas promovidas por escolas de governo e 199 promovidas por instituições privadas, totalizando 268 capacitações, que ocorreram junto a servidores da universidade pertencentes a 91 unidades de trabalho.

O quadro 5 realiza um comparativo de gastos e capacitações, comparando com o ano 
de 2017, e é interessante ressaltar que não há como comparar os gastos com relação às concessões de diárias e passagens, pois antes de 2018 tas gastos não eram especificados para a Ação. Da forma aqui apresentada houve um controle de gastos na Ação e possibilidade de rastreamento de suas informações.

Tabela 5

Comparativo de gastos e capacitações 2017-2018. Elaboração própria.

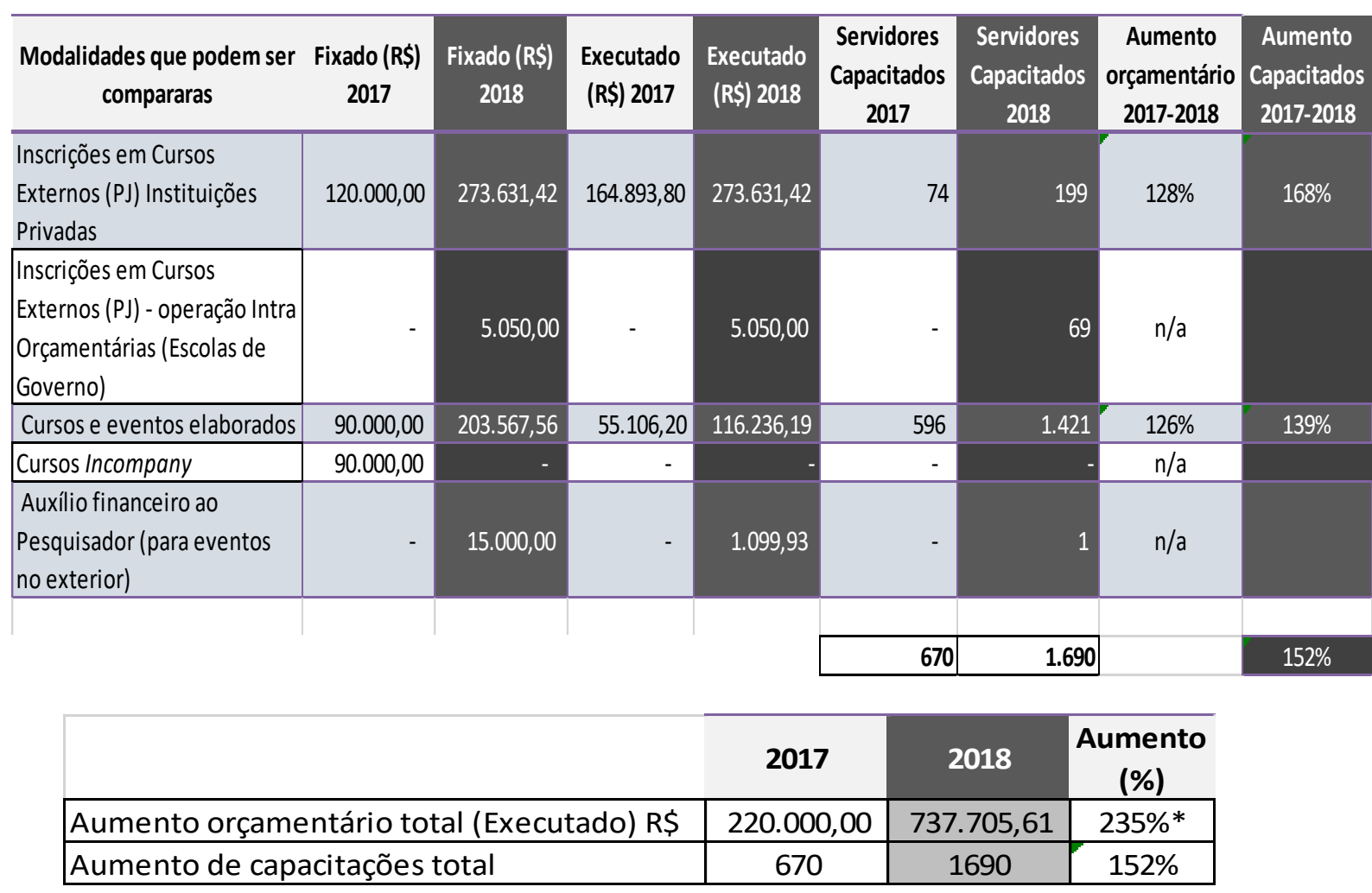

Observou-se ainda, que a instituição de fluxos formais de acesso aos cursos, elaborados em conformidade com a legislação vigente, trouxe maior segurança para os atores envolvidos e ordenadores de despesa da Instituição.

\section{Considerações finais}

A elaboração, aprovação e realização do PAC-2018 foi um momento histórico para a Instituição, com relação à capacitação de servidores técnicos administrativos. Mas nada destas realizações poderiam ser concretizadas sem o apoio da alta gestão, que foi fundamental para abrir caminhos antes inacessíveis culturalmente para técnicos administrativos.

Entender que o técnico administrativo necessita de valorização e desenvolvimento e que isto é vital para uma IFES significa entender que o trabalho do docente não é completo 
sem o trabalho do técnico administrativo, e vice-versa. As duas categorias são essenciais em uma IFES e merecem o olhar estratégico na motivação, capacitação e preparo emocional.

O PAC e o PQI se mostraram valiosos instrumentos de valorização funcional e desenvolvimento institucional, abrindo caminhos para a criação de equipes multidisciplinares de trabalho, projetos, e para maior interação entre as áreas.

Dezoito meses após o início na intervenção observou-se que o cumprimento das ações propostas no PAC-2018 aumentou sobremaneira o trabalho da CODEP, e a procura maior por cursos ensejou a pesquisa e divulgação de cursos externos relevantes e cadastramento dos servidores em um banco de capacitação, alocando-os nas trilhas. Esta atividade estava sendo realizada em planilhas manuais e a utilização de um sistema informatizado tornaria este trabalho mais ágil.

Mas todo este esforço pareceu recompensado pelo sentimento de valorização do técnico administrativo que foi evidente na Universidade e com esse sentimento foi possível alavancar outros trabalhos que antes caminhavam a passos curtos, como o entendimento da necessidade de mapeamento de processos, e a adequação dos processos de contratação às INs de licitação.

Como sugestão de novas pesquisas ou continuidade desta, sugerimos: (a) a curto prazo, a verificação da relação dos cortes orçamentários da Universidade em 2019 e a afetação da capacitação estratégica; (b) a médio prazo, a verificação da rotatividade de funcionários - em número e tempo de saída - após o PAC-2018 e o PQI na Universidade; e (c) a longo prazo, a inscrição nas trilhas de capacitação e sua relação com os futuros gestores.

\section{Referências}

AMARAL, Helena Kerr do. Desenvolvimento de competências de servidores na administração. Brasília, Revista do Serviço Público, n.57, v.4 p.549-563, Out./Dez. 2006.

BACON, Kevin. Além da capacitação: desenvolvimento de líderes para o setor público. Brasília, Revista do Serviço Público, Ano 50, n.4, p.81-91, Out./Dez. 1999.

BRANDÃO, Hugo Pena; BAHRY, Carla Patrícia. Gestão por competências: métodos e técnicas para mapeamento de competências. Brasília, Revista do Serviço Público, v.2, n.56, p.179-194, Abr./Jun. 2005. 
BRASIL. Presidência da República. Lei n. 4320, de 17/03/1964. Estatui Normas Gerais de Direito Financeiro para elaboração e controle dos orçamentos e balanços da União, dos Estados, dos Municípios e do Distrito Federal. Disponível em: < http://www.planalto.gov.br/ccivil_03/leis/14320.htm>. Acesso em: 21 jul. 2019.

BRASIL. Presidência da República. Lei n. 8.666, de 21/06/1993. Regulamenta o art. 37, inciso XXI, da Constituição Federal, institui normas para licitações e contratos da Administração Pública e dá outras providências. Disponível em: < http://www.planalto.gov.br/ccivil_03/leis/18666cons.htm> Acesso em: 21 jul. 2019.

BRASIL. Ministério da Educação. Lei n. 9394, de 20/12/1996. Estabelece as Diretrizes e Bases da Educação Nacional. Disponível em: http://www.planalto.gov.br/ccivil_03/leis/19394.htm> Acesso em: 21 jul. 2019.

BRASIL. Presidência da República. Lei n. 11.091, de 12/01/2005. Dispõe sobre a estruturação do Plano de Carreira dos Cargos Técnico-Administrativos em Educação, no âmbito das Instituições Federais de Ensino vinculadas ao Ministério da Educação, e dá outras providências. Disponível em: < http://www.planalto.gov.br/ccivil_03/_ato20042006/2005/lei/111091.htm>. Acesso em: 21 jul. 2019.

BRASIL. Presidência da República. Decreto no 5.707, de 23 de fevereiro de 2006. Institui a Política e as Diretrizes para o Desenvolvimento de Pessoal da administração pública federal direta, autárquica e fundacional, e regulamenta dispositivos da Lei $\mathrm{n}^{\mathrm{o}} 8.112$, de 11 de dezembro de 1990. Disponível em: http://www.planalto.gov.br/ccivil_03/Ato20042006/2006/Decreto/D5707.htm. Acesso em: 21 jul. 2019.

BRASIL. Presidência da República. Lei no 6.096, de 24 de abril de 2007. Institui o Programa de Apoio a Planos de Reestruturação e Expansão das Universidades Federais - REUNI.. Disponível em: http://www.planalto.gov.br/ccivil_03/_ato20072010/2007/decreto/d6096.htm>. Acesso em: 21 jul. 2019.

BRASIL. Presidência da República. Lei no 8.112, de 11 de dezembro de 1990. Dispõe sobre o regime jurídico dos servidores públicos civis da União, das autarquias e das fundações públicas federais. Disponível em: http://www.planalto.gov.br/ccivil_03/leis/L8112cons.htm>. Acesso em: 21 jul. 2019.

BRESSER-PEREIRA, Luiz Carlos.; SPINK, Peter. Gestão do Setor Público: Estratégia e estrutura para um novo Estado. Rio de Janeiro: FGV, 1998. Disponível em: < http://www.plataformademocratica.org/Publicacoes/7562_Cached.pdf>. Acesso em: 10 jul. 2019.

CHANLAT, Jean-François. O gerencialismo e a ética do bem comum: a questão da motivação para o trabalho nos serviços públicos. In: VII Congresso Internacional del CLAD sobre la Reforma del Estado y de la Administración Pública, Lisboa, Portugal em 2002.

FLEURY, Maria Tereza Leme; FLEURY, Afonso. Construindo o conceito de competência. Curitiba, Revista de Administração Contemporânea, Edição Especial, p.183-196. 2001. 
GEMELLI, Inês Maria Picoli, FILIPPIM, Eliane Salete. Gestão de Pessoas na Administração Pública: o desafio dos municípios. RACE, Unoesc, v. 9, n. 1-2, p. 153-180, jan./dez. 2010.

GODOY, Maria Tereza. Qualificação do Servidor Público: Implicações na Gestão de Pessoas na Universidade Federal de Goiás. In: XXXVIII Encontro da ANPAD, 2014, Rio de Janeiro, Brasil. p. 1-15.

LIMA, Elaine da Silva. Motivação Individual e Contrato Psicológico para Atuar no Grupo de Trabalho: O caso dos servidores técnico administrativos do Campus Seropédica da UFRRJ. 110. Dissertação de Mestrado em Administração - UFRRJ, Rio de Janeiro, Agosto de 2017

OLIVEIRA FILHO, Adão. Política de Gestão de Pessoas em Instituições Federais de Ensino Superior: uma Análise dos Subsistemas Capacitação e Aperfeiçoamento e Avaliação de Desempenho. 189. Dissertação de Mestrado em Administração - UFSC, Santa Catarina, Agosto de 2012.

PREDES, Fabiane da Silva de Lemos. A implementação do Programa de Apoio a Planos de Reestruturação e Expansão das Universidades Federais (REUNI): consensos e dissensos na Universidade Federal Rural do Rio de Janeiro (UFRRJ). 161. Dissertação de Mestrado em Ciências Sociais - UFRRJ, Rio de Janeiro, Março de 2015.

PEREIRA, A.L.C; SILVA A.B. As competências gerenciais nas instituições federais de educação superior. Cadernos EBAPE. BR. Rio de Janeiro, ed. Especial 9, Art.9, p.627-647, jul. 2011.

RODRIGUES, Ana Cristina de Albuquerque Lima. Aprendizagem e Desenvolvimento de Competências Gerenciais nas IFES: Uma análise indutiva das práticas de gestão utilizadas pelos Coordenadores da Pós-Graduação Stricto Sensu da UFRRJ. 108. Dissertação de Mestrado em Administração - UFRRJ, Rio de Janeiro, Abril de 2017.

SILVA, F.M.V e CUNHA, C.J.C.A. A transição de contribuidor individual para líder: a experiência vivida pelo professor universitário. Revista GUAL, Florianópolis, v. 5, n. 1, pp. 145-171, jan./fev./mar./abr. 2012.

SILVA, Gilberto Soares; SILVA, Andreia de Carvalho. Gestão de Pessoas no Serviço Público: os programas de capacitação de servidores técnico administrativos na Universidade Federal do Tocantins - Campus de Araguaína. Estudo \& Debate, Lajeado, v. 25, n. 2, p. 41-65, 2018.

SOF - Secretaria de Orçamento Federal. Manual Técnico de Orçamento. MINISTÉRIO DO PLANEJAMENTO, DESENVOLVIMENTO E GESTÃO. Brasília, 2017. Disponível em < http://www.orcamentofederal.gov.br/informacoes-orcamentarias/manual-tecnico/mto_20171a-edicao-versao-de-06-07-16.pdf>. Acesso em 28 jul. 2019. 
UFRRJ. Plano Anual de Capacitação 2018. Institui o novo plano de capacitação aprovado pelo Conselho Universitário na Deliberação 5/2018. Disponível em http://institucional.ufrrj.br/codep/files/2018/03/PAC-2018_UFRRJ-vers\%C3\%A3o-final1.pdf>. Acesso em 07 jul. 2019.

UFRRJ, Deliberação 15 de 23/03/2012. Aprova as modificações do Estatuto da Universidade, a Reforma do Regimento Geral e revoga as deliberações 81/2010, 104/2010 e 014/2011. Rio de Janeiro, 2012. Disponível em < http://www.ufrrj.br/soc/DOCS/Delib\%200152012\%20CONSU\%20-\%20ESTATUTO\%20e\%20REGIMENTO.pdf>. Acesso em 13 jul. 2019.

\footnotetext{
'Manutenção de serviços, gastos com pessoal civil e militar ativos e pensionistas, material de consumo, juros, dentre outros.

ii Portal da Secretaria de Orçamento Federal. Acesso em 24 jul 2019.

iii Dispõe sobre o Sistema de Planejamento e Gerenciamento de Contratações e sobre a elaboração do Plano Anual de Contratações de bens, serviços, obras e soluções de tecnologia da informação e comunicações no âmbito da Administração Pública federal direta, autárquica e fundacional.
} 